http://dx.doi.org/10.18675/1981-8106.vol26.n51.p112-125

\title{
Práticas Aritméticas na Formação de Professores da Escola Normal da Província do Rio de Janeiro
}

\author{
Practices Aritmethics in Teachers Training at Normal School of Rio de Janeiro \\ Province
}

Prácticas Aritméticas en la Formación de Maestros de la Escola Normal de la Provincia del Rio de Janeiro

Kátia Sebastiana Carvalho dos Santos Farias'

'Universidade Federal de Rondônia-(UNIR), Rondônia - Brasil. E-mail: katiafarias2014@gmail.com

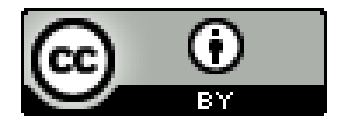

Educação: teoria e prática, Rio Claro, SP, Brasil - eISSN: 1981-8106

Está licenciada sob Licença Creative Common

\section{Resumo}

Este texto resultou da pesquisa que tem como objetivo investigar práticas mobilizadoras de cultura aritmética que teriam sido realizadas na Escola Normal da Província do Rio de Janeiro, no período de 1868 a 1889, com o propósito de formar professores para atuarem nas chamadas "escolas de primeiras letras". Analisou-se, entre outros documentos, relatórios dos Presidentes da Província do Rio de Janeiro apresentados à Assembleia Legislativa Provincial do Rio de Janeiro (1835-1889); relatórios do Diretor da Escola Normal e relatórios do Diretor da Instrução Pública. Com relação às práticas de ensino de Aritmética na formação de professores, viu-se que, a partir dos anos de 1870, foi recomendado o método intuitivo, inspirado na obra "Cours théorique et pratique de pédagogie et de méthodologie », de Thomas Braun. Recomendação efetivada no uso do "Compendio de Pedagogia" de Antonio Marciano da Silva Pontes, onde se encontra rastros de que a Aritmética passa a ser escolarizada com forte vertente moralizadora. Porém, verificou-se que o método intuitivo não foi bem recebido pelos professores primários.

Palavras-chave: Cultura Aritmética; Escola Normal da Província do Rio de Janeiro; Formação de Professores. 


\begin{abstract}
This text resulted from research which has as objective to investigate the mobilizing practices of an arithmetical culture that had been taught at Normal School of Rio de Janeiro Province, from 1868 to 1889, which the purpose was to prepare teachers to act on "escolas de primeiras letras:. We had analyzed among other documents, reports of Rio de Janeiro Province Presidents presented to Provincial Legislative Assembly of Rio de Janeiro (1835-1889); reports of Director of Normal School and reports of Public Instruction Director. Regarding the Arithmetical teaching practices in teachers' formation we had seen that, from 1870, it was recommended the intuitive method, inspired on Thomas Braun Cours théorique et pratique de pédagogie et de méthodologie. Recommendation took effect in the use of Antonio Marciano da Silva Pontes' Compendio de Pedagogia, where we could find tracks that the Arithmetical become schooled with the strong moralizing strand. But the intuitive method was not well accepted by elementary teachers.
\end{abstract}

Keywords: Arithmetical Culture; Normal School of Rio de Janeiro Province; Teachers Education.

\title{
Resumen
}

Este texto es el resultado de la investigación que tiene como objetivo explorar prácticas movilizadoras de cultura aritmética que fueron realizadas en la Escola Normal de la Provincia del Rio de Janeiro, en el período de 1868 hasta 1889, con el propósito de formar maestros para la enseñanza en las llamadas “ escuelas de las primeras letras”. Se analizó, dentre otros documentos, informes de los Presidentes de la Provincia del Rio de Janeiro, presentados a la Assembleia Legislativa Provincial del Rio de Janeiro (1835 - 1889), informes del Director de la Escola Normal e informes del Director de la Instrução Pública. Con relación a las prácticas de la enseñanza de Aritmética en la formación de maestros, se vió que, a partir de los años de 1970, fue recomendado el método intuitivo, inspirado en la obra "Cours theorique et pratique de pédagogie et de méthologie", de Thomas Braun. Recomendación efectivada en el uso del "Compendio de Pedagogia" de Antonio Marciano da Silva Pontes, donde se halló señales de que la Aritmética empieza a ser escolarizada con fuerte vertiente moralizante. Pero, se verificó que el método intuitivo no fue bien recibido por los maestros de la primaria.

Palabras clave: Cultura Aritmética; Escola Normal de la Provincia del Rio de Janeiro; Formación de Maestros.

\section{Introdução}


Este texto trata de uma pesquisa desenvolvida em nível de doutorado- intitulada "Práticas mobilizadoras de cultura aritmética na formação de professores da Escola Normal da Província do Rio de Janeiro (1868-1889): ouvindo espectros imperiais"- tem como objetivo rastrear memórias de práticas aritméticas realizadas na Escola Normal, no contexto da formação de professores de instrução primária para atuarem nas chamadas "escolas de primeiras letras". Buscamos entender como as práticas de cultura aritmética foram mobilizadas na formação matemática promovida pela primeira Escola Normal do Brasil.

Ao buscarmos rastrear memórias de práticas aritméticas realizadas na Escola Normal, temos como propósito constituir tais práticas no presente, através de um procedimento remissivo analógico, o que nos leva a ponderar que tal atitude deverá estar inevitavelmente imbricada com rastros de condicionantes normativos advindos do contexto de atividade de pesquisa em que nos situamos e dos propósitos que orientam a nossa própria pesquisa, a qual se insere no campo temático da história da educação matemática. Esse propósito se fortalece no nosso entendimento de que os estudos historiográficos, conforme Miguel (2010), buscam entender a forma como as práticas se realizam sob os condicionamentos das transformações temporais de diferentes contextos de atividade humana.

A partir dessa visão, entendemos que um dos pontos fortes de pesquisas de natureza histórica é o levantamento da base documental, e que um dos momentos cruciais da atividade de investigação do historiador consiste em constituir documentos - isto é, "textos" considerados pertinentes, e lê-los comparativamente, com base em alguma concepção filosófica, explícita ou implícita, acerca da natureza da relação que subsiste entre práticas discursivas e demais práticas sociais relativas ao evento sob investigação, de acordo com Miguel (2010), visando esclarecê-lo segundo os propósitos orientadores da pesquisa.

Foi muito importante, no processo da pesquisa, a leitura dos trabalhos da professora Heloísa Villela ${ }^{1}$. Encontramos no corpo de suas referências, a informação de que a Escola Normal da Província do Rio de Janeiro já havia sido objeto de investigação dessa pesquisadora no mestrado em 1990 e no doutorado em 2002. Essa era uma das possibilidades da viabilização da pesquisa: localizar e selecionar as fontes; encontrar rastros; obter trabalhos legados para discussões para, então, buscar ressignificá-los à luz de nossos objetivos. Entendemos que esse é o movimento da desconstrução defendido por Jacques Derrida (1986). É um movimento sempre sujeito a novos contextos, novas leituras e novas constatações e interrogações.

Entendemos que na pesquisa histórica, estamos lidando com jogos de linguagem performados pela prática da escrita, precisamos nos colocar nos rastros de outros jogos de linguagem que possam nos auxiliar a significar de modo adequado as questões que desejamos esclarecer. Nesse caso, enfatizamos que, na interação com os textos de Heloísa Villela,

\footnotetext{
${ }^{1}$ Heloísa de Oliveira Santos Villela, professora $\mathrm{Dr}^{\mathrm{a}}$ da Universidade Federal Fluminense (UFF). 
criamos um outro texto, uma outra narrativa ${ }^{2}$. Nesse sentido, é importante a observação de Derrida (1986), o que interessa na leitura de um texto não é criticar de fora ou tentar explicálo, mas encontrar na estrutura heterogênea do texto, tensões ou contradições.

Apoiados nesse entendimento, constituímos a base documental da pesquisa. Grande parte dos textos que integra o corpus da pesquisa foi localizada na Biblioteca Nacional do Rio de Janeiro, no Setor de Obras Raras e no Arquivo Público do Estado do Rio de Janeiro. Apenas o "Compendio de Pedagogia", de Antonio Marciano da Silva Pontes, localizamos na Biblioteca Paulo Bourroul, da Faculdade de Educação da Universidade de São Paulo (FEUSP). Organizamos um quadro com o objetivo de explicitar melhor as fontes.

Quadro 1- Fontes da Pesquisa

\begin{tabular}{|c|c|c|c|}
\hline $\begin{array}{l}\text { Tipificação } \\
\text { das fontes }\end{array}$ & $\begin{array}{l}\text { Especificação das fontes } \\
\text { constituídas }\end{array}$ & $\begin{array}{l}\text { Autores, atores e/ou } \\
\text { comunidades destinatárias }\end{array}$ & $\begin{array}{l}\text { Contextos de atividade } \\
\text { humana cujos rastros de } \\
\text { memória são mobilizados por } \\
\text { práticas aritméticas }\end{array}$ \\
\hline Relatórios & $\begin{array}{l}\text { Relatórios enviados anualmente à } \\
\text { Assembleia Legislativa da } \\
\text { Província do Rio de Janeiro no } \\
\text { século XIX. }\end{array}$ & $\begin{array}{l}\text {-Presidentes da Província; } \\
\text {-Diretor Instrução Primária; } \\
\text {-Diretor da Escola Normal. }\end{array}$ & $\begin{array}{l}\text { - Gestão da atividade } \\
\text { educativa escolar; } \\
\text {-Gestão da atividade de } \\
\text { instrução aritmética; } \\
\text {-Gestão da atividade de } \\
\text { formação de professores. }\end{array}$ \\
\hline Jornais & $\begin{array}{l}\text {-“A Instrução Publica”; semanal, } \\
\text { custeado pelo governo, elaborado } \\
\text { e distribuído na Província do Rio } \\
\text { de Janeiro. Público alvo: } \\
\text { professores públicos e } \\
\text { funcionários do Ministério do } \\
\text { Império; } \\
\text { - “A Verdadeira Instrução } \\
\text { Pública”. Órgão dos professores } \\
\text { públicos de instrução primária da } \\
\text { Corte. Relator: Manuel José } \\
\text { Pereira Frazão. Iniciou suas } \\
\text { edições em } 15 \text { de junho de } 1872 .\end{array}$ & $\begin{array}{l}\text { - Diretor da Escola Normal; } \\
\text { - Professores. }\end{array}$ & $\begin{array}{l}\text { - Atividades midiáticas em } \\
\text { geral; } \\
\text { - Atividade de mídias } \\
\text { formativas, educativas e/ou } \\
\text { voltadas para professores, } \\
\text { pais e autoridades escolares. }\end{array}$ \\
\hline Revistas & $\begin{array}{l}\text { - "O Ensino Primário"; mensal, } \\
\text { redigida por professores primários } \\
\text { da Província do Rio de Janeiro; } \\
\text { - "Revista do Ensino"; editada } \\
\text { mensalmente; } \\
\text { - "A Escola": Revista Brasileira } \\
\text { de Educação e Ensino. }\end{array}$ & $\begin{array}{l}\text { - Professores Formadores; } \\
\text { - Professores; } \\
\text { - Literatos. }\end{array}$ & $\begin{array}{l}\text { - Atividades midiáticas em } \\
\text { geral; } \\
\text { - Atividade de mídias } \\
\text { formativas, educativas e/ou } \\
\text { voltadas para professores, } \\
\text { pais e autoridades escolares. }\end{array}$ \\
\hline
\end{tabular}

\footnotetext{
${ }^{2}$ Entendemos com McDonald (1994) que o ato narrativo é aquele que constrói e produz em parte a história. E quanto mais nós consideramos essa história completa e acabada, atribuindo a ela um significado fixo e confiável, tanto mais nós acabamos interferindo e mudando os valores daquilo que constitui o ato narrativo. O que constitui $\mathrm{o}$ ato narrativo é o processo de construir e produzir a história.
} 


\begin{tabular}{|c|c|c|c|}
\hline $\begin{array}{l}\text { Provas } \\
\text { escritas }\end{array}$ & $\begin{array}{l}\text { Provas de aritmética (anos de } \\
1870 \text { e } 1888 \text { ) realizadas por } \\
\text { alunos da escola Normal da } \\
\text { Província do Rio de Janeiro. }\end{array}$ & $\begin{array}{l}\text {-Alunos; } \\
\text {-Professores. }\end{array}$ & $\begin{array}{l}\text { - Avaliação da aprendizagem } \\
\text { da Aritmética escolar na } \\
\text { Escola Normal da Província } \\
\text { doRio de Janeiro. }\end{array}$ \\
\hline $\begin{array}{l}\text { Compêndios } \\
\text { e } \\
\text { Curso }\end{array}$ & $\begin{array}{l}\text { - "Elementos de Arithmetica", de } \\
\text { Ottoni (adotado na Escola Normal } \\
\text { no período de } 1868 \text { a 1878); } \\
\text { - "Curso de Aritmética } \\
\text { Elementar", de Bernardo Alves } \\
\text { Carneiro; } \\
\text { - "Compendio de Pedagogia", de } \\
\text { Antonio Marciano da Silva Pontes } \\
\text { (adotado na 1ª cadeira: } \\
\text { Pedagogia); } \\
\text { - "Cours Théorique et Pratique de } \\
\text { Pédagogie et de Métholologie", de } \\
\text { Braun. }\end{array}$ & $\begin{array}{l}\text {-Autores: Ottoni; Carneiro; } \\
\text { Braun e Pontes; } \\
\text { - Professores Formadores; } \\
\text {-Futuros professores; } \\
\text {-Pais; } \\
\text {-Outras comunidades. }\end{array}$ & $\begin{array}{l}\text { - Produção e circulação de } \\
\text { textos de Aritmética } \\
\text { destinados ao campo de } \\
\text { atividade educativa escolar; } \\
\text { - Produção e circulação de } \\
\text { textos pedagógicos destinados } \\
\text { à formação de professores. }\end{array}$ \\
\hline $\begin{array}{l}\text { Tipificação } \\
\text { das fontes }\end{array}$ & $\begin{array}{l}\text { Especificação das fontes } \\
\text { constituídas }\end{array}$ & $\begin{array}{l}\text { Autores, atores e/ou } \\
\text { comunidades destinatárias }\end{array}$ & $\begin{array}{l}\text { Contextos de atividade } \\
\text { humana cujos rastros de } \\
\text { memória são mobilizados por } \\
\text { práticas aritméticas }\end{array}$ \\
\hline $\begin{array}{l}\text { Livros } \\
\text { de Aritmética } \\
\text { (1519-1679) }\end{array}$ & $\begin{array}{l}\text { - "Aritmética como descrição do } \\
\text { Real (1519-1679)". Vol. I e II } \\
\text { (ALMEIDA); } \\
\text { - De las Cuentas y las Escrituras. } \\
\text { In: "Summa de Aritmetica, } \\
\text { Geometria, Proportioni et } \\
\text { proportionalita" (LUCA } \\
\text { PACIOLI); } \\
\text { - "Tratado da Prática } \\
\text { Darismetyca" (GASPAR } \\
\text { NICOLAS); } \\
\text { - "Muhammad iben Musa Al- } \\
\text { khawarizmi- Le Calcul Indien } \\
\text { (Algarismus)" (ANDRÉ } \\
\text { ALLARD). }\end{array}$ & $\begin{array}{l}\text { - Autores: Almeida; Pacioli; } \\
\text { Nicolas e Allard; } \\
\text { - Comunidades mercantis, } \\
\text { astronômicas, astrológicas, } \\
\text { religiosas, etc. }\end{array}$ & $\begin{array}{l}\text { - Produção e circulação de } \\
\text { textos de Aritmética } \\
\text { destinados a diferentes } \\
\text { campos de atividade humana } \\
\text { (comercial, financeiro, } \\
\text { astronômico, etc.). }\end{array}$ \\
\hline
\end{tabular}

Fonte: Farias (2014, p. 44).

A nossa leitura dos jogos narrativos - relatórios, jornais, revistas, dentre outros levou-nos a produzir um novo jogo narrativo de linguagem no qual praticamos não apenas uma interdiscursividade entre essas narrativas, bem como entre elas e outros jogos de linguagem, produzidos em diferentes campos da atividade humana, com a finalidade de ampliar o horizonte de visibilidade das práticas mobilizadoras de cultura aritmética na formação de professores na Escola Normal da Província do Rio de Janeiro. 


\section{Escolas Normal e Primária na Província do Rio de Janeiro}

Houve grandes brados de esperança de que a Escola Normal da Província do Rio de Janeiro viria, em poucos anos, formar considerável número de cidadãos habilitados "convenientemente" para a instrução primária. Mas, então, a quem interessava que a Escola Normal fosse desativada tão cedo e por quê? Como entender que o Estado que institui formação de professores, investindo na criação de escolas normais, em outros momentos promova a extinção das mesmas?

São reminiscências de um mundo onírico. A avaliação dos elementos oníricos à hora do despertar é um caso modelar de raciocínio dialético. Por isso é que o pensamento dialético é o órgão do despertar histórico. Cada época não apenas sonha a seguinte, mas, sonhando, se encaminha para o seu despertar. Carrega em si o seu próprio fim e - como Hegel já o reconheceu — desenvolve-o com astúcia. (BENJAMIN, 2006, p. 43).

O Presidente Couto Ferraz expediu no ano de 1849 o Regulamento da Instrução Primária e Secundária, no qual deixava clara sua intenção de adotar o Sistema Austríacoholandês. Isso mesmo! A formação de professores pela prática. A Escola Normal ficou desativada por mais de uma década, finalmente, em 1859, uma lei provincial autorizava a sua recriação ${ }^{3}$.

Dessa forma, o contexto da cena "Escolas Normal e Primária na Província do Rio de Janeiro" está situado numa visão de educação e instrução própria da segunda metade do século XIX. A Província do Rio de Janeiro, nessa época, necessitava de reformas administrativas e políticas que, sem dúvida, envolviam a educação, a qual era campo de intensos debates no período em foco. Nesse sentido, o projeto formativo de caráter positivista da Escola Normal, a partir do ano de 1868, defendia uma educação que transformasse o homem comum de modo a pô-lo a serviço da regeneração da sociedade, isto é, de um projeto político civilizador, desenvolvimentista e progressivista de cunho liberal-meritocrático.

Podemos dizer ainda que, a Província do Rio de Janeiro por volta dos anos de 1870 vivia períodos de efervescência e de profundas mudanças na política e na sociedade. Nesse clima, os professores do magistério público primário da Província do Rio de Janeiro, muitos deles formados na Escola Normal, discutiam problemas educacionais e sociais que julgavam importantes, bem como publicavam suas ideias nos Jornais como "A Instrução Pública" e ainda em revistas como "A Escola" - Revista de Educação e Ensino. Em diferentes mídias impressas, produzidas no interior de um mesmo campo de atividade humana - o campo do jornalismo impresso -, os professores questionavam as decisões políticas do império brasileiro, que eram tomadas única e exclusivamente na Corte, sede da monarquia. Como por exemplo:

\footnotetext{
${ }^{3}$ Regulamento da Instrução Primária e Secundária, de 14de dezembro de 1849. 
Tudo existe, se dirige e se encaminha de acordo com as ideias expressas nos regulamentos formulados pelo governo. Repito sim! E isto se dá também aqui como em toda a parte; e se, alhures, é difícil lutar contra a vontade do poder, em parte alguma a dificuldade é tamanha como entre nós, onde o poder tem vontade e só ele pode querer (REVISTA A ESCOLA - REVISTA DE EDUCAÇÃO E ENSINO, 1878, p. 35).

Estamos entendendo como Foucault (1979) que não existe "o poder"; mas sim relações de poder, ou seja, formas díspares, heterogêneas, em constante transformação. Nesse entendimento, o poder é uma prática social e acrescentamos, ainda, cultural, que se constitui historicamente.

\section{Práticas Curriculares de Cultura Aritmética}

Como as práticas de cultura aritmética foram mobilizadas na formação matemática promovida pela primeira Escola Normal do Brasil? Conforme Hérbard (1990), alguns estudos apontam para o fato de que a aritmética escolar deriva da cultura mercantil e passa a ser disciplinarizada, isto é, constituída como uma disciplina escolar, a partir do século XVIII. Vejamos o caso da Inglaterra. O ensino de aritmética foi introduzido nas escolas britânicas, aproximadamente, em 1750, a partir do mercado, ou seja, de práticas mercantis. O currículo baseava-se no que se chamava "aritmética concreta", entendida como um conjunto heterogêneo de unidades de pesos, medidas e os equivalentes, utilizados em diferentes ramos do comércio. Nesse contexto, segundo Lave (2002), o comércio fornecia os "meios de estruturação" para o currículo escolar.

Explicando melhor a expressão "meios de estruturação", em seu texto "Do lado de fora do supermercado", Jean Lave apresenta alguns exemplos para explicar o conceito de "meios de estruturação" (LAVE, 2002, p. 3). Lave (2002) se pergunta sobre como as atividades se reúnem e dão forma umas às outras nas diferentes oportunidades e quais são os processos que geram diferenças qualitativas entre as atividades aritméticas e, ainda, quais são os meios de estruturação aplicados numa dada situação, para dar forma e significado a relações quantitativas. Nesse exemplo, Jean Lave defende que as ações dão forma umas às outras, mas não necessariamente da mesma maneira, vejamos:

Eu posso ler enquanto faço tricô. Algumas vezes o processo de tricotar dá forma ao processo da leitura. Eu poderia ler enquanto tricotasse uma fileira, mas esperar para virar a página até que a fileira estivesse terminada, ou interromper a leitura para apanhar um ponto que houvesse escapado. Outras vezes, leio até o final da página antes de começar uma nova fileira, tricotando mais rapidamente conforme o enredo vai se complicando, ou apertando um pouco os pontos quando cresce a tensão. Os planos de fazer tricô parecem mais promissores se não exigirem uma atenção constante, ao 
passo que os livros de capa dura são mais atraentes porque as páginas permanecem abertas mais facilmente. Fazer tricô é um meio de estruturação para o processo de leitura, e a leitura fornece meios de estruturação que dão forma e pontuação ao processo de fazer tricô. As atividades dão forma uma à outra, mas não necessariamente de maneira idêntica. Habitualmente, uma atividade vai progredindo e condicionando a forma da outra, mais do que sendo condicionada por ela (LAVE, 2002, p.5).

Trazendo esse exemplo para o campo da matemática, em oposição a uma concepção de aprendizagem universal, Lave formula o entendimento de que a aprendizagem matemática está condicionada pelas situações em que ocorre. É o valor da situação que condiciona as práticas. O "meio de estruturação" é a forma, ou seja, a estrutura específica que uma prática matemática adquire conforme a atividade e o meio no qual tal atividade se passa; assim, na perspectiva de Lave, o conhecimento se constitui no agir (LAVE, 1996 apud VILELA, 2006). Entendemos que alguns interesses e atividades do mercado podem ter influenciado os meios de estruturação do currículo escolar em meados do século XVIII, na Inglaterra, definindo a organização das atividades pedagógicas, bem como os conteúdos de ensino. Enfim, entendemos que as práticas mobilizadoras de cultura aritmética que teriam sido realizadas na Escola Normal da Província do Rio de Janeiro poderiam ter mobilizado memórias de rastros de significado de práticas mercantis.

Encontramos rastros de duas tradições de livros de Aritmética para diversos campos de atividade humana, ou seja, dois tipos de obras que mobilizam a cultura aritmética: livros destinados à prática mercantil e livros escolares, alguns desses destinados a formar o formador, como o "Compendio de Aritmética" de Cristiano Benedito Ottoni. Por exemplo, o programa de ensino da Escola Normal, datado de 1869, normatiza para a segunda cadeira (Aritmética): “Aritmética e sistema legal de pesos e medidas”, que o professor proporá problemas que tenham analogia com a vida real, com a economia doméstica, rural e industrial. Encontramos, ainda, rastros de que a Aritmética passa a ser escolarizada com uma intensa vertente moralizadora; essa visão está fortemente colocada no "Compendio de Pedagogia", elaborado por Antonio Marciano da Silva Pontes. Mas, de qualquer forma, nesta investigação, pensamos em nos deixar orientar, dentre outras, pela seguinte questão: os modos de se lidar com unidades de medida diferentes, por exemplo, ligadas a contextos de práticas comerciais de compra e venda de diferentes tipos de mercadorias teriam, inicialmente, inspirado práticas escolares de ensino de Aritmética em nosso país e, por extensão, práticas de ensino de aritmética na formação de professores da Escola Normal da Província do Rio de Janeiro?

O projeto político pedagógico dessa época defendia que os professores dessem ao ensino caráter prático e útil, como lhes eram recomendados sempre que havia, para isso, ocasião. O menino, mesmo na escola, deveria saber prestar à família serviços que dependem do que está aprendendo; e não os prestaria, por certo, se somente lhe sobrecarregassem a memória de teorias que não compreenderia, de problemas absurdos pelo fantástico das premissas. Raras vezes se exigia que fizessem uso da inteligência, por ela resolvesse questões e problemas simplicíssimos que todos os dias se apresentavam na vida comum. 
Como consta no jornal “A Instrução Publica" (1872), o Diretor de Instrução Pública reclamava da insuficiência do ensino ministrado nas escolas e sobre a ineficácia dos métodos adotados no ensino elementar. Assim, desde os anos setenta, em todos os ramos do ensino, o respectivo professor deveria seguir o melhor método, o mais adaptado à escola primária, esforçando-se para que seus alunos o compreendessem de modo que pudessem por si mesmos, aplicá-lo na escola. Dizia o relatório do Diretor da Província do Rio de Janeiro (1889): a partir dos anos setenta do século XIX, a função social da escola primária mudou; passou a ter características especiais. Uma delas, por exemplo, é a de atender aos milhares de indivíduos saídos da escravidão, na maior ignorância, sem crenças, sem noção dos deveres, e que precisam receber, na escola, a instrução e a educação necessárias para sua completa regeneração ${ }^{4}$. Uma outra característica especial da nova função social da escola é a de atender também à grande afluência de imigrantes em nosso solo, cujos interesses intelectuais e morais não podem ser indiferentes àqueles que dirigem os destinos da sociedade. À instrução primária prendem-se altos problemas sociais e políticos, sendo necessário prever e encaminhar os acontecimentos para que não se desviem da senda dos interesses nacionais.

Essa visão nos remete a outros contextos espaço-temporais, mais especificamente ao filme "Escolarizando o mundo", o qual discute o papel da educação escolarizada e defende que a educação não é simplesmente a transmissão de informação, é de fato a aculturação, ou a doutrinação, isto é, a imposição de formas de saber, aprender, ser e comportar-se. Essas diferentes formas criam diferentes seres humanos. A escola ao longo dos anos tem tido como tradição fazer uso de métodos de disciplina que se recusam a levar em consideração o sujeito cultural situado e encarnado. A escola desenvolve o poder de afastar-se do mundo exterior. Nessa ótica, a cultura da escola não é trivial, não é decorativa, não é penas e sinos, não é dança, nem mesmo rituais. A cultura escolar é o cobertor de valores morais e éticos com o qual o indivíduo é coberto 5 .

\section{0 "Compendio ${ }^{6}$ de Pedagogia" de Pontes na Formação de Professores da Escola Normal}

Como consta no Relatório do Diretor da Escola Normal da Província do Rio de Janeiro (1868), a cadeira ${ }^{7}$ de Pedagogia foi, a partir do ano de 1868, ocupada pelo professor Antonio Marciano da Silva Pontes, que elaborou apostilas para suas aulas inspirado no «Cours

\footnotetext{
${ }^{4}$ No Rio de Janeiro da fase imperial, prevaleceu a crença positivista comteana na escola e no teatro como instituições regeneradoras da sociedade.

${ }^{5}$ Filme "Escolarizando o Mundo". http://www.youtube.com/watch?v=6t_HN95-Urs

6 A palavra "compêndio" foi utilizada para nomear livros produzidos com a finalidade de ensino.

${ }^{7}$ No contexto do diálogo espectral da pesquisa, a palavra "cadeira" foi usada para designar um conjunto de disciplinas. A título de exemplo, no contexto da Escola Normal da Província do Rio de Janeiro, no ano de 1868, a $2^{\text {a }}$ cadeira estava organizada do seguinte modo: no primeiro ano (Aritmética e Metrologia); no segundo ano (Álgebra, Geometria e Desenho Linear); no terceiro ano, (Aplicações de Matemática à Escrituração Mercantil, à Química, à Física, à Mecânica, à Agrimensura e ao Desenho Linear).
} 
théorique et pratique de pédagogie et de méthodologie», de Thomas Braun $^{8}$, e, posteriormente, o Senhor Pontes elaborou o «Compendio de Pedagogia », obra que, a partir da década de oitenta, passou a fazer parte da formação dos alunos da Escola Normal da Província do Rio de Janeiro, na Escola Anexa à Escola Normal.

Vimos que a Aritmética é tratada no "Compendio », na terceira parte, capítulo V, "Methodo de Arithmetica". Diz o « Compendio »: "Nem todas as crianças são dotadas para o cálculo". Por quê? "Falta de talento especial". Para as crianças que começariam o estudo da Aritmética, essa deveria ser puramente mental. Ou seja, o uso e o estudo da parte prática da Aritmética deveriam preceder, necessariamente, a um ensino mais completo e ao mesmo tempo mais teórico. Na visão de Pontes (1981, p.158), o cálculo verbal seria da maior utilidade nos usos da vida e convinha habituar a criança, desde muito cedo, a executá-lo por meio de exercícios verbais. Para as crianças que ainda não sabiam escrever, não poderia ser de outro modo o ensino de Aritmética.

Entretanto, "é imperioso não se enganar sobre a significação do cálculo mental, como aqui empregamos", dizia Pontes (1881, p. 158). Com efeito, tratava-se de memória, e de operações um tanto mecanicamente executadas, como resultados de esforços e de hábito. Por fim, afirmava Pontes:

O ensino da Aritmética depende, em grande parte, da maneira por que tais matérias se acham expostas nos compêndios adotados e dos quais o professor não se pode afastar muito, sem burlar as disposições regulamentares a que o ensino público está sujeito. E, por isso mesmo, o professor público não tem livre escolha dos compêndios pelos quais tem de ensinar; assim, o professor deve ter cuidado em poder tirar o maior partido daqueles a que tiver de cingir-se (ibidem, p.161).

No "Compendio de Pedagogia », vimos que não se deveria aguardar uma época determinada para começar o ensino da Aritmética. Mas, todos os alunos deveriam receber o ensino de Aritmética segundo o grau de adiantamento em que se achavam e conforme seu desenvolvimento intelectual permitisse.

\section{Algumas Considerações}

Ao nos colocarmos interdiscursivamente nos "rastros de práticas mobilizadoras de cultura aritmética no contexto de atividade de formação de professores na Escola Normal da Província do Rio de Janeiro", encontramos rastros de duas tradições de livros de Aritmética para diversos campos da atividade humana, ou seja, dois tipos de obras que mobilizam a cultura aritmética: livros destinados à prática mercantil e livros escolares, alguns desses

\footnotetext{
${ }^{8}$ Thomas Braun nasceu em 1814 e faleceu no ano de 1906. Professor de Metodologia e Pedagogia na Escola Normal de Nívelles. Foi inspetor de Escolas Normais.
}

Educação: Teoria e Prática/ Rio Claro/ Vol. 26, n.51/ p. 112-125/ Jan-Abr. 2016. 
destinados a formar o formador, como o livro "Elementos de Arithmetica" (1855) de Cristiano Benedito Ottoni.

Os compêndios de Aritmética de Cristiano Benedito Ottoni e de Bernardo Alves Carneiro foram usados na formação dos alunos-mestres, na segunda cadeira (Aritmética).

Num primeiro momento, o uso da Aritmética mercantil foi rastreado e pudemos verificar a importância dada à unidade "pesos e medidas" nos currículos escolares de Aritmética, não apenas no Brasil, mas também na Inglaterra e em Portugal. Por último, entendemos que a presença da unidade denominada "números complexos" na Aritmética de Ottoni e nas de outros brasileiros e portugueses, como, por exemplo, as aritméticas de Eduardo de Sá Pereira de Castro (1883) "Explicador de Arithmetica", pode ser entendida como o "rastro" de uma crença no poder e força de práticas matemáticas mercantis (e, portanto, extraescolares), relativamente a práticas aritméticas escolares e livrescas de caráter abstrato, universal e estrutural, postas em circulação por perspectivas pedagógicas "inovadoras" posteriores.

O que estamos compreendendo por "números complexos"? "Chama-se "número complexo" o que consta de partes, cada uma exprimindo as unidades diversas, que resultam da divisão de uma unidade principal" (OTTONI, 1855, p.77). Continuou explicando Ottoni:

\begin{abstract}
a) Unidades de comprimento - A braça divide-se em duas varas. A vara em cinco palmos. O palmo em oito pollegadas. A pollegada em doze linhas. Para medidas itinerárias usam-se da milha, que consta de 841 3/4 braças (são 1/60 do comprimento de um gráo do Meridiano terrestre). E da legoa, composta de 3 milhas (1/20 do gráo do Meridiano); b)Unidades de superfície. - As áreas se medem por braças quadradas, palmos quadrados, etc., e pode adoptar-se para medida agrária a Geira, ou 400 braças quadradas; c) Unidades de capacidade. - Para líquidos. O almude que se divide em 12 canadas; e a canada em 4 quartilhos. Para seccos. O moio constando de 60 alqueires: o alqueire de 4 quartas; d) Unidades de peso - É a principal a arroba, que consta de 32 libras. Divide-se a libra em 2 marcos : o marco em 8 onças: a onça em 8 oitavas : a oitava em 72 grãos. Empregam-se para os grandes pesos o quintal de 4 arrobas e a tonellada de 54; e) Unidades de tempo - Para medir o tempo, é geralmente escolhido por unidade o dia, dividido em 24 horas: a hora em 60 minutos: o minuto em 60 segundos: este uso é universal no mundo civilizado. Se, porém, adotamos somente as divisões e subdivisões admitidas pelo uso, e que têm nomes especiais, os números assim formados se chamam complexos (ibidem, p.78).
\end{abstract}

Nesse sentido, a presença dos "números complexos" nos compêndios de Aritmética, bem como nos currículos relativos à formação de professores no período temporal aqui em foco, poderia ser vista como uma espécie de "resistência" manifestada por práticas de medição baseadas em usos e costumes - e que constituíam uma constelação de "aritméticas das práticas", isto é, de aritméticas efetivamente praticadas em diferentes contextos de atividade humana e que mantinham entre si "semelhanças de família" - à gradativa 
constituição de um tipo único, uniforme, genérico, abstrato e universal de "aritmética escolar" que viria a ser posteriormente praticada, imprimindo à diversidade viva e operante das "aritméticas das práticas" o rótulo de "práticas tradicionais". Encontramos, ainda, rastros de que a Aritmética passa a ser escolarizada com uma intensa vertente moralizadora, de maneira mais veemente no "Compendio de Pedagogia", elaborado por Antonio Marciano da Silva Pontes.

Vimos que, a partir dos anos de 1870, em todos os ramos do ensino, o professor deveria seguir o melhor método, o mais adaptado à escola primária, ou seja, o intuitivo. Essa recomendação efetiva-se no uso do "Compendio de Pedagogia" de Pontes, adotado na cadeira de Pedagogia, na Escola Anexa à Escola Normal da Província do Rio de Janeiro, local da formação prática dos alunos-mestres. Mas esse método não foi bem aceito pelos professores primários, pois eles entendiam que se tratava apenas de "prática e mais prática", com muitos exemplos e poucas regras, muitas aplicações e poucas teorias e abstrações, principalmente com relação à Aritmética; por isso, resistiram ao método intuitivo, preferindo utilizarem-se do método que já vinham desenvolvendo, o "tradicional".

Enfim, ouvimos muitas vozes que ecoaram dos relatórios e jornais analisados. São espectros. Um "verdadeiro" clamor em prol do progresso moral e intelectual do povo por meio da instrução pública. A educação popular foi um dos títulos que mais honrou o século XIX. Mas como o ensino da Aritmética contribuiu para esse intento? Para Pontes (1881), a Aritmética, como os outros ramos do ensino primário, tem seu ponto de vista intelectual e moral e tem um lugar entre os meios de educação. Entendemos que são rastros da filosofia Positivista de Comte.

Na performance da escrita desta narrativa entendemos, de acordo com Farias (2014), que os textos diferem e ditam suas próprias leituras e que nenhum contexto exclui outros contextos. Um texto não pode ser entendido como um conjunto de posições homogêneas, pelo contrário, é sempre heterogêneo. Há sempre possibilidades de encontrarmos, no texto estudado, algo a questionar e até mesmo a desconstruir, tal como defende Derrida. Nessa visão, entendemos que não nos interessa, na leitura de um texto, criticar de fora ou tentar explicá-lo, mas encontrar, na sua estrutura heterogênea, tensões ou contradições. Esperamos que a narrativa aqui produzida como resultado deste trabalho de pesquisa possa contribuir para outros jogos de remetimentos no campo da história da educação matemática.

\section{Referências}

BENJAMIN, W. Passagens. Belo Horizonte: UFMG; São Paulo: imprensa oficial do Estado de São Paulo, 2006.

CASTRO, E. S. P. Explicador de Arithmetica. 6. ed. Alves \& Cia. Rio de Janeiro, 1883. 
DERRIDA, J. Del materialismo no dialéctico. Entrevista con Kadhim Jihad, Culturas, 69, 3 de agosto de 1986, pp. 03-05. Disponível em:

<http://www.jacquesderrida.com.ar/textos/materialismo.htm>. Acesso: 03.02.2013.

FARIAS, K. S. C. dos S. Práticas mobilizadoras de cultura aritmética na formação de professores da Escola Normal da Província do Rio de Janeiro (1868-1889): ouvindo espectros imperiais. 2014. Tese (Doutorado em Educação) - Faculdade de Educação da Universidade Estadual de Campinas (UNICAMP), Campinas, 2014.

FOUCAUlT, M. Microfísica do Poder. (Org. Trad.) Robert Machado. Rio de Janeiro: Edições Graal, 1979.

HÉBRARD, J. A escolarização dos saberes elementares na época moderna. Teoria \& Educação. Porto Alegre: Artes Médicas, 1990, n. 2, p. 65-110.

LAVE, J. Do lado de fora do supermercado. In: FERREIRA, M.K.L. Ideias matemáticas de povos culturalmente distintos. Global: São Paulo, 2002.

MCDONALD, H. The narrative act: Wittgenstein and narratology. In: Telos: Critical Theory of Contemporary, vol. IV. 4, 1994.

MIGUEL, A. Percursos indisciplinares na atividade de pesquisa em história (da educação matemática): entre jogos discursivos como práticas e práticas como jogos discursivos.

Bolema, v. 35, pp. 1-57. Rio Claro-SP: UNESP, 2010.

MIGUEL, A; VILELLA, D; MOURA, A. R. L. Desconstruindo a matemática escolar sob uma perspectiva pós-metafísica de educação. Zetetiké, Campinas CEMPEM-FE/UNICAMP, v. 18, n. temático, p. 123-195.

PONTES, A. M. S. Compendio de Pedagogia: para uso dos alunos da Escola Normal da Província do Rio de Janeiro. 3. ed. Nictheroy, 1881.

SOARES, F. S. Professores - autores de compêndios de Matemática no século XIX. In: XII CIAEM-IACME, Recife, 2011. Anais eletrônicos... Recife, 2011. Disponível em: <http://www.cimm.ucr.ac.cr/ocs/files/conferences/1/schedConfs/>. Acesso em: 20.03.2012.

VILELA, D. S. Notas sobre a matemática escolar no referencial sócio-histórico-cultural. Horizontes, Itatiba/SP, v. 24, n.1, p. 43-50, jan./jun. 2006. Disponível em: < http://www.saofrancisco.edu.br/edusf/publicacoes/RevistaHorizontes/Volume_01/uploadAddr ess/Art4\%5B6172\%5D.pdf>. Acesso em: 10.04.1012. 
VILLELA, H. O. S. A primeira escola normal do Brasil: uma contribuição à história da formação de professores. 1990. Dissertação (Mestrado em Educação) - Universidade Federal Fluminense, (UFF), 1990.

VILLELA, H. O. S. A. Da palmatória à lanterna mágica: a Escola Normal da Província do Rio de Janeiro entre o artesanato e a formação profissional (1868-1876). 2002. 291f. Tese (Doutorado em Educação)- Faculdade de Educação da Universidade de São Paulo, São Paulo, 2002.

WITTGENSTEIN, L. Investigações Filosóficas. Petrópolis: Vozes, 1996.

\section{Fontes}

RIO DE JANEIRO. Relatório do Diretor da Escola Normal, José Carlos de Alambary, 19 de julho de 1869. Anexo ao Relatório do Vice-Presidente desembargador Diogo Teixeira de Macedo, de 1 de outubro de 1869.

RIO DE JANEIRO. Relatório do Diretor de Instrução Publica (M. Ribeiro de Almeida) anexado ao relatório apresentado á Assembleia Legislativa Provincial do Rio de Janeiro pelo presidente, conselheiro Carlos Affonso de Assis Figueiredo. Rio de Janeiro, julho de 1889.

Revista

A Escola - Revista de Educação e Ensino, 1878.

Recebido em: 18/03/2014

Aprovado para publicação em: 20/04/2016

Publicado em: 30/04/2016 